\title{
Martius Flap for Iatrogenic Rectovaginal Fistula: When to do a Diverting Stoma?
}

\author{
Mohamed A Nada, MD; Mahmoud Farghaly, MD \\ Department of General Surgery, Ain Shams University, Egypt
}

Rectovaginal fistula (RVF) is a major problem following mainly an obstetric trauma with high rate of recurrence inspite of different techniques of repair. The need for routine diverting stoma is another matter of debate.

Aim of the work: To evaluate the outcome of RVF repair using Martius flap with and without diverting stoma.

Patients and Method: Twenty six patients with RVF were divided into 2 groups, one without colostomy (group A) and the second with (group B).

Results: Postoperative wound infection was $33 \%$ in group A \& $9 \%$ in group B. Early failure in group A was $13 \%$ and $0 \%$ in group $B$, whereas late failure was $6.6 \% \& 9 \%$, in group $A$ \& group B, respectively.

Conclusion: It is advised to perform pre-repair diverting stoma to improve the outcome in RVF with large defects, presence of vaginitis, or postradiation.

Key words: Rectovaginal fistula, Martius flap, diversion stoma.

\section{Introduction}

Rectovaginal fistula (RVF) is a very distressing disease with profound negative psychological and social impact. It is defined as an abnormal epithelialized communication between the rectal and the vaginal cavities causing passage of the flatus and/or stool from the vagina, with recurrent vaginal infections. ${ }^{1}$

The most common cause of RVF is obstetric trauma during vaginal delivery which represents $30-88 \%$ of all iatrogenic RVF.1,2 However, it could be manifested after vaginal, anal or perineal surgeries $(7 \%))^{3}$ It may complicate introduction of foreign bodies into the vagina and it could complicate Crohn's disease (6-23\%)., ${ }^{4,5}$ Obstetric rectovaginal fistulas may be accompanied with obstetric sphincter injuries as the mechanism of trauma can initiate both. ${ }^{4}$

RVF is classified according to the etiology, location, size and complexity. The scheme based on location, classifying fistulae as being low, mid, or high depends on the fistula's opening into the rectum, with "low fistula" has an opening near the dentate line. Fistulas are considered small if the diameter of "the opening" is less than $0.5 \mathrm{~cm}$, medium $0.5-2.5 \mathrm{~cm}$ and large when $>2.5 \mathrm{~cm}$, keeping in mind that there is no definitive track in this special version of fistulas. RVF are considered complex if they are large, high, recurrent or caused by inflammatory bowel disease. ${ }^{6}$
Repair of RVF is a challenge even to expert surgeons due to the high failure rate, which may be attributed to the communication between a positive pressure septic cavity (rectum) and a negative pressure cavity (vagina) with very thin layer separating both cavities hence easily infected.?

Different techniques of repair were described varying from primary repair, flaps, and even using meshes, with different approaches either local "transvaginal, perineal, transanal" or abdominal approach for proximal fistulas that couldn't be accessed from the previous approaches. Proctectomy could be the only line of definitive treatment in fewer situations. ${ }^{8,9}$

Martius flap has been described for RVF repair. It is a very simple pedicle flap procedure, with a success rate ranging from 60 to $100 \%$, in which the bulbocavernosus muscle with the surrounding fibroadipose tissue of the labia majora are interposed at the rectovaginal space through a subcutaneous tunnel preserving the posteroexternal vascular pedicle. ${ }^{10-12}$

The need for diverting colostomy for RV fistula is a matter of debate among surgeons. Theoretically it may improve the outcome by preventing soiling and consequent infection especially in the early postoperative period, but on the other hand doing a stoma adds more distressing situation to the patients. This necessitates careful selection of 
patients that would have improved outcome of RVF repair by adding a diverting stoma. ${ }^{13-15}$

\section{Aim of the work}

Evaluation of the outcome after RVF repair using Martius flap with and without performing a diverting stoma and to establish criteria for selecting patients that would benefit from performing a stoma prior to RVF repair.

\section{Patients and methods}

26 patients with rectovaginal fistulas were recruited from our outpatient clinic at Ain Shams University Hospital between 2015 and 2016, approval of the Ain Shams University Surgical Institutional Ethical Committee was obtained in addition to an informed patient consent explaining the details of the procedure and its potential complications.

Detailed history was taken from patients to identify the cause of fistula and presence of fecal incontinence according to Wexner incontinence score.

Digital rectal and vaginal examination was performed in all patients to confirm the diagnosis of fistula and its location and to assess if there is gross vaginal contamination.

Endo-anal ultrasonography was done for every patient to measure the diameter of the rectal aspect of the fistula and to identify if there is combined anal sphincter defect.

Patients with malignant fistulas, Crohn's disease, major anal sphincter defect (more than $1 / 3$ of the sphincter circumference) and patients with sphincter defects exceeding the anterior part of the anal sphincter were all excluded from our study.

\section{We classified the patients into $\mathbf{2}$ groups:}

Group A: patients without stomas and the defect diameter less than $5 \mathrm{~mm}$ measured by endoanal ultrasonography.

Group B: Patients presented to our clinic with stomas, patients with defect size equal to or more than $5 \mathrm{~mm}$, patients with history of pelvic irradiation, and patients with severe vaginal contamination with stool regardless of the size of the defect as measured by endoanal ultrasound.

\section{Surgical technique:}

Diverting loop sigmoid colostomy was offered 6 to 10 weeks prior to the definitive RVF repair for those patients in group B not having stomas.

Colonic preparation or wash through the distal limb of colostomy and rectal enema were performed the day before surgery.

Patients were positioned in extended lithotomy position, with proper sterilization of the anal canal, vagina and perineum.

Urinary catheter was inserted. Intraoperative re-assessment of the fistula was done (Figure 1). Adrenaline diluted in normal saline solution at a concentration of 1:200.0000 was injected subcutaneously in the perineal space extending into the submucosal plane of the posterior vaginal wall, to induce vasoconstriction and to reduce the bleeding at the plane of dissection. Transverse perineal skin incision was done extending to the subcutaneous tissue (Figure 2), the dissection was advanced into the plane between the anal sphincter posteriorly and the posterior wall of the vagina anteriorly (using low unipolar coagulation forces) till separating both walls from each other, isolating the fistula and dissecting further cranially to at least 1.5 to $2 \mathrm{~cm}$ full thickness healthy anterior rectal wall, after disconnecting the fistula, we trimmed the defects in the adjacent walls of both cavities (Figure 3) then the rectal defect was

Table 1: Demographic data, previous repair, associated anal sphincter injury, postoperative wound infection and failure rates in both groups

\begin{tabular}{|c|c|c|c|}
\hline & Group A n:15 & Group B n:11 & Total n:26 \\
\hline Mean age & 27.66 years & 35.09 years & 30.8 years \\
\hline Etiology & $\begin{array}{l}\text { Obstetric trauma } \\
\mathrm{n}: 15\end{array}$ & $\begin{array}{ll}\text { - } & \text { Obstetric trauma n: } 8 \\
\text { - } & \text { Defloration injury n: } 1 \\
\text { - } & \text { Post LAR + XR n: } 1\end{array}$ & $\begin{array}{l}\text { Obstetric trauma } \\
\text { n: } 23(88.8 \%)\end{array}$ \\
\hline History of previous RVF repair & 0 & $4(36.4 \%)$ & $4(15.4 \%)$ \\
\hline Associated anal sphincter injury & $3(20 \%)$ & $2(18.2 \%)$ & $5(19.2 \%)$ \\
\hline PO wound infection & $5(33.3 \%)$ & 1 & $6(23.1 \%)$ \\
\hline Early failure of surgery & $2(13.3 \%)$ & 0 & $2(7.7 \%)$ \\
\hline Late failure & $1(6.7 \%)$ & $1(9.1 \%)$ & $2(7.7 \%)$ \\
\hline Total failure & $3(20 \%)$ & $1(9.1 \%)$ & $4(15.4 \%)$ \\
\hline
\end{tabular}

LAR: low anterior resection XR: external beam radiotherapy 
closed in two layers the first by using interrupted absorbable $3 / 0$ mucosal stitches and the second layer was $3 / 0$ delayed absorbable PDS muscular stitches. Martius flap was created (unilateral, left labia) through a longitudinal $3 \mathrm{~cm}$ labial incision (Figure 4), and the fibro adipose flap was dissected carefully from the surrounding tissues, preserving its posterolateral pedicle, a subcutaneous tunnel connecting the labial wound and perineal wound was created and the flap was transposed. The flap was placed between the vagina and the repaired rectum and sutured by interrupted absorbable sutures to the rectal wall over the rectal defect closure line, both the labial incision and the vaginal defect were closed by interrupted absorbable sutures (Figure 5). In the presence of anal sphincter injury, the repair of the exposed sphincter was performed (edge to edge) using delayed absorbable PDS $3 / 0$ in interrupted manner. Proper hemostasis was followed by irrigation of the wound using garamycin saline solution (80 mg garamycin in $50 \mathrm{ml}$ normal saline). The skin was then closed with wide interrupted absorbable $2 / 0$ stitches.

Postoperatively, urinary catheter was removed on the next day. IV ciprofloxacin $500 \mathrm{mg} / 12$ hours with metronidazole $500 \mathrm{mg} / 8$ hours were given for the next three days. Patients in group A continued nil per os for three consecutive days then began regular diet. Patients in group B started oral intake on the same day. We prescribed oral ciprofloxacin $500 \mathrm{mg}$ twice daily and metronidazole $500 \mathrm{mg}$ three times for one week starting from the fourth postoperative day, with bulk laxative granules once daily for 2 months.

Care of the wound was done by twice daily dressing using normal saline $500 \mathrm{ml} /$ garamycin $160 \mathrm{mg}$ solution followed by application of topical garamycin cream then covering the wound with sterile gauze, for patients in group $A$, the dressing was done meticulously specially after defecation.

Patients were discharged on $3^{\text {rd }}$ and $5^{\text {th }}$ postoperative days for group $B$ and group A, respectively after teaching them how to look after their wounds, if there was wound infection, the patient discharge was postponed until complete clinical subsidence of the infection.

Postoperative follow-up visits were done every 2 weeks for two months then monthly for the next 4 months. Patients were instructed to seek an OPD visit for any anal or unexplained vaginal discharge, perineal pain or swelling, at follow-up visits, patients were questioned about fecal soiling from the vagina, anal and/ or vaginal pain, and Wexner incontinence scores were measured in group $A$.
We relied on careful perineal inspection for signs of inflammation, whereas DRE was postponed till the 2 month visit to avoid interruption of the natural healing process.

Three months post-repair if there were no signs of failure in group $B$, we restored the continuity of bowel and then calculated the Wexner score.

Early failure was defined as persistence or recurrence of symptoms within the first two postoperative months, while late failure was defined as recurrence of symptoms and / or identification of the fistula opening into the rectum while performing digital rectal examination (DRE) after the $2^{\text {nd }}$ postoperative month which was supported by endoanal ultrasound findings.

Wexner score improved significantly postoperatively in 4 patients (more than or equal to $50 \%$ reduction in the score value), and one patient had a limited improvement (30\% reduction). All the 5 patients with combined RVF and anal sphincter repair didn't show any symptoms or signs of failure during the follow-up period.

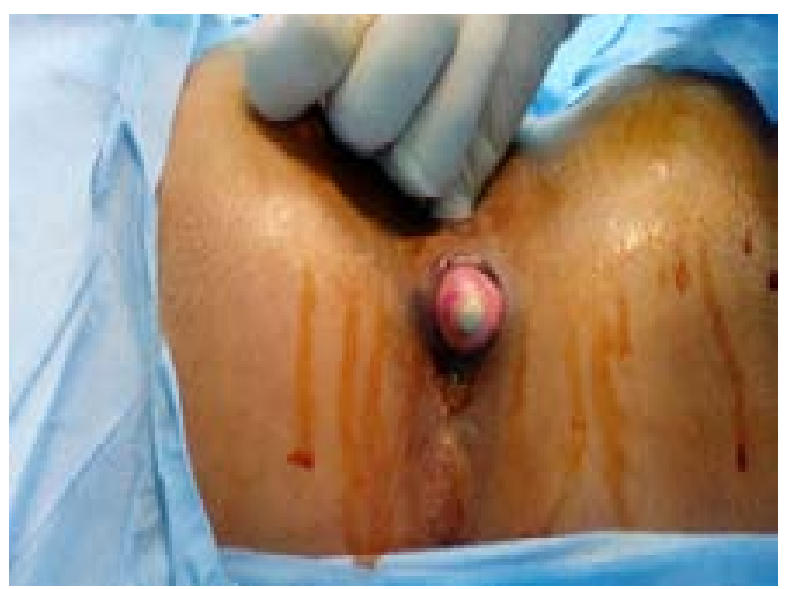

Fig 1: Per-vaginal examination under general anaesthesia prior to the procedure.

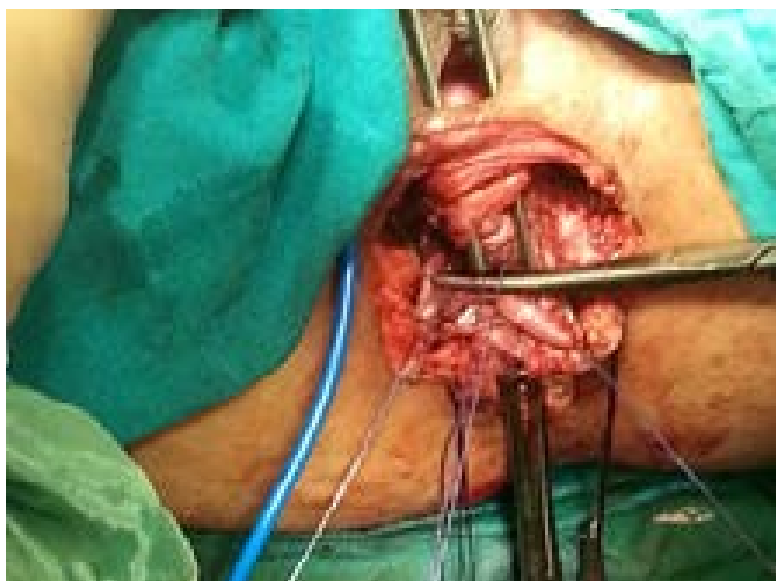

Fig 2: Perineal dissection in a plane between sphincter complex and posterior vaginal wall Forceps is inserted at the vaginal side of the fistula coming out in the perineum, where the fistula is divided. 


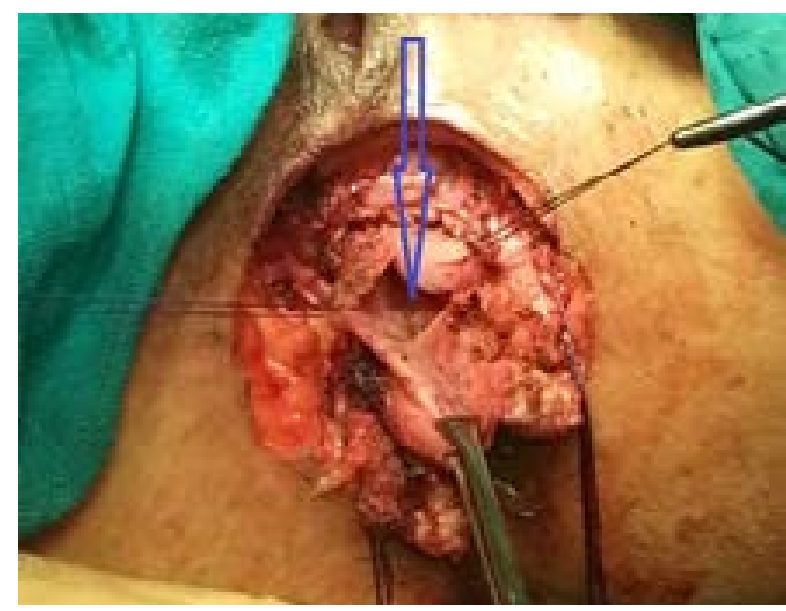

Fig 3: Rectal side of the fistula (blue arrow) is trimmed and prepared for repair.

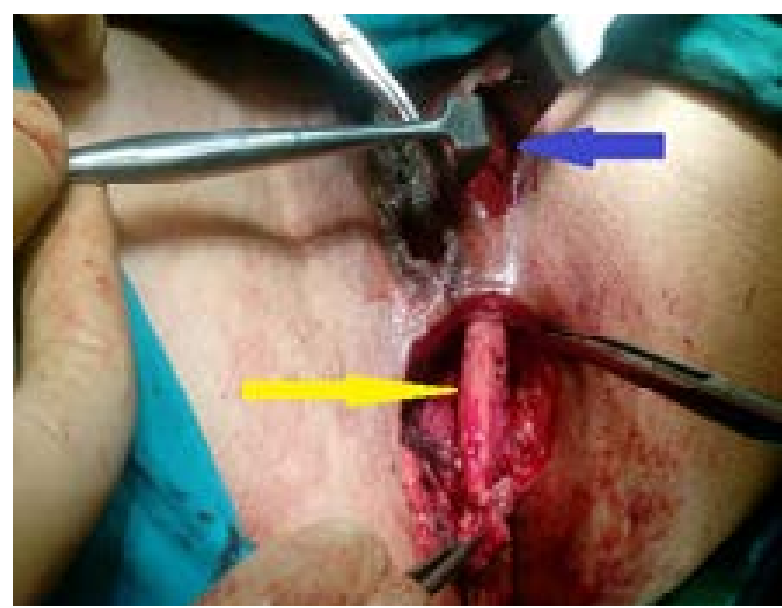

Fig 4: Skin incision done over left labia majora (blue arrow) and a fibro-adipose flap (yellow arrow) is dissected and passed through subcutaneous tunnel to the perineal wound where it is interposed between vagina and rectum.

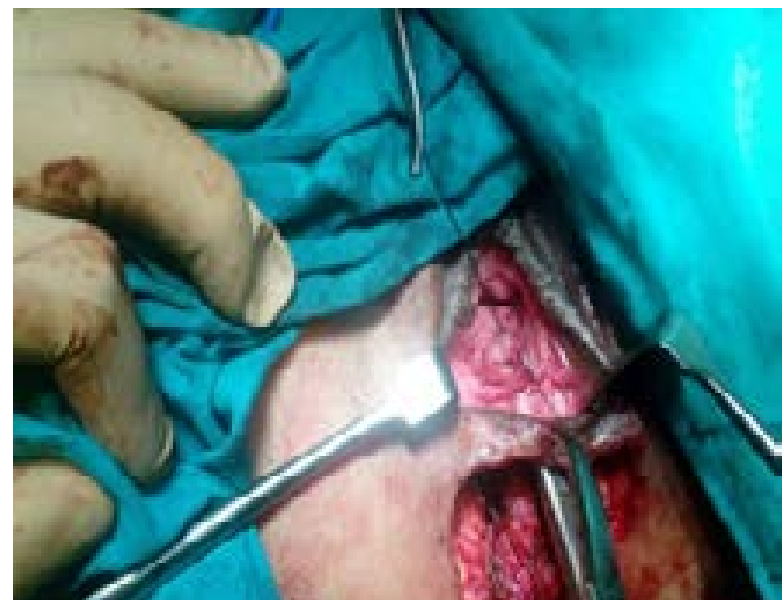

Fig 5: The vaginal side of the fistula is trimmed and repaired by interrupted stitches using absorbable suture.

\section{Discussion}

The mean age for the patients in this study was 30.8 years with obstetric trauma being the cause of the fistula in more than $88 \%$.

We had one patient with defloration injury [trial of rupturing the hymen using hard object]. It is a bizarre form of foreign body introduction into the virgin's vagina intending to rupture the hymen before the first normal sexual intercourse after marriage and it is still practiced in few rural areas in Egypt, this type of vaginal trauma can lead to a severe vaginal injury and development of RVF.

Outcome of Martius flap for RVF repair has been addressed in few studies showing a success rate varying between 60 to $100 \%$. Unfortunately, the number of patients in each study didn't exceed 20. ${ }^{13-15}$

The disadvantages of simple repair were discussed in different studies. Insufficient tissue mobilization and excessive tension particularly at the area where the line of simple suture repair of both organs meet or overlap. This overlapping of sutures therefore present the recipe for future failure. ${ }^{16,17}$

Koscinski and Sekowska offered their patients with low RVF and anal sphincter injury a combined approach of anal sphincter reconstruction plus advancement flap for repairing the RVF. ${ }^{18}$

In this series, combining RVF surgery with anterior anal sphincter repair didn't add to the failure rate $(0 \%)$. Instead, there was marked improvement of postoperative psychological status of patients as a consequence of enhanced continence.

The postoperative success rate was $80 \%$ in group $A$ versus $90 \%$ in group $B$, whereas the infection rate was $33.33 \%$ and $9 \%$ in group $A$ and group $B$, respectively. The lower incidence of both infection and failure rates in group $B$, despite the complexity of the fistulae, may be explained by the presence of diverting stomas constructed prior to definitive repair.

The construction of diverting stoma long before fistula surgery does not only prevent postoperative wound soiling but also permits time for cure of vaginitis which could be reflected on less incidence of postoperative infection and eventually less incidence of failure. Having mentioned that, we believe that it isn't reasonable to do diverting stoma in every patient eligible for RVF repair.

Bauer et al, 1991 and Halverson et al, 2001 in two separate studies support our conclusion as they stated that fecal diversion is performed only in complicated cases, and should not be advised for 
every fistula repair. ${ }^{19,20}$

\section{Conclusion}

Using Martius flap for RVF repair is a favorable technique and when combined with simultaneous anal sphincter repair yield an excellent functional and psychological outcome with no extra morbidities. Preoperative diverting stoma is recommended before the repair of assumed "complex" fistulas.

\section{References}

1. Pinto RA, PetrsonTV, Shawki S, Davila GW, Wexner SD: Are there predictors of outcome following rectovaginal fistula repair? Dis Colon Rectum 2010; 53: 1240-1247.

2. Rivadeneira DE, Ruffo B, Amrani S, Salinas C: Rectovaginal fistulas: Current surgical management. Clin Colon Rectal Surg 2007; 20: 96-101.

3. ForsgrenC,AltmanD: Riskofpelvicorganfistulain patients undergoing hysterectomy. Current Opinion Obst Gynecol 2010; 22: 404-407.

4. Saclarides TJ. Rectovaginal fistula: Surg Clin North Am 2002; 82: 1261-1272.

5. Sands BE, Blank MA, Patel K, van Deventer SJ, Study AL: Long-term treatment of rectovaginal fistulas in Crohn's disease: Response to infliximab in the ACCENT II Study. Clinical Gastroenterol \& Hepatol 2004; 2: 912-920.

6. Debeche-Adams $\mathrm{TH}, \mathrm{BOHL}$ Jl. Rectovaginal fistulas. Clin Colon Rectal Surg 2010; 23: 99103.

7. Devesa JM, Devesa M, Velasco GR, Vicente $R$, García-Moreno $F$, et al: Benign rectovaginal fistulas: management and results of a personal series. Tech Coloproctol 2007; 11: 128-134.

8. Casadesus D, Villasana L, Sanchez IM, Diaz $\mathrm{H}$, Chavez M, et al: Treatment of rectovaginal fistula: A 5-year review. Aust $\mathbf{N} \boldsymbol{Z} \mathbf{J}$ Obstet \& Gynaecol 2006; 46: 49-51.

9. Champagne BJ, McGee MF: Rectovaginal fistula. Surg Clin North Am 2010; 90: 69-82.
10. Cui $L$, Chen $D$, Jiang $H$ : Interposition of vital bulbocavernosus graft in the treatment of both simple and recurrent rectovaginal fistulas. International J Colorectal Dis 2009; 24: 12551259.

11. McNevin MS, Lee PY, Bax TW: Martius flap: An adjunct for repair of complex, low rectovaginal fistula. Am J Surg 2007; 193: 597-599.

12. Pitel S, Lefevre JH, Chafai N, Shields C, Tiret E: Martius advancement flap for low rectovaginal fistula: Short- and long-term results. Colorectal Dis J 2011; 13: 112-115.

13. ee PY, Fazio VW, Church JM, Hull TL, Eu KW, et al: Vaginal fistula following restorative proctocolectomy. Dis Colon Rectum 1997; 40: 752-759.

14. Piekarski JH, Jereczek-Fossa BA, Nejc D, Pluta P, Szymczak W, et al: Does fecal diversion offer any chance for spontaneous closure of the radiation-induced rectovaginal fistula? Int J Gynecol Cancer 2008; 18: 66-70.

15. Zhu YF, Tao GQ, Zhou N, Xiang C: Current treatment of rectovaginal fistula in Crohn's disease. World J Gastroenterol 2011; 17: 963967.

16. Mazier WP, Senagore AJ, Schiesel EC: Operative repair of anovaginal and rectovaginal fistulas. Dis Colon Rectum 1995; 38: 4-6.

17. Naru T, Rizui JH, Talati J: Surgical repair of genital fistulae. J Obst Gynecol Res 2004; 30: 293-296.

18. Koscinski T, Sekowska M: Surgical treatment of rectovaginal fistulas. Polish J Surg 2007; 79: 533-539.

19. Bauer JJ, Sher ME, Jaffin $H$, Present $D$, Gelerent I: Transvaginal approach for repair of rectovaginal fistula complicating Crohn's disease. Annals Surg 1991; 213: 151-158.

20. Halverson AL, Hull TL, Fazio VW, Church J, Hammel J, Floruta C: Repair of recurrent rectovaginal fistulas. Surgery 2001;130:753757. 